\title{
Age and Growth of the Anglerfish Lophiomus setigerus in the East China Sea
}

\author{
Michio Yoneda, ${ }^{* 1}$ Muneharu Tokimura, ${ }^{* 2}$ Hitoshi Fujita, ${ }^{* 3}$ Naohiko Takeshita, ${ }^{* 4}$ \\ Koji Takeshita, ${ }^{* 5}$ Michiya Matsuyama, ${ }^{* 1}$ and Shuhei Matsuura ${ }^{* 1}$
}

\author{
*1Department of Fisheries, Faculty of Agriculture, Kyushu University, Hakozaki, Fukuoka 812-8581, Japan \\ *2Seikai National Fisheries Research Institute, Kokubu, Nagasaki 850-0951, Japan \\ *3 Tohoku National Fisheries Research Institute, Shinhama, Shiogama 985-0001, Japan \\ ${ }^{*}$ Department of Applied Aquabiology, National Fisheries University, Nagata-Honmachi, \\ Shimonoseki 759-6595, Japan \\ *5Formerly: Department of Biology and Aquaculture, National Fisheries University, Nagata-Honmachi, \\ Shimonoseki 759-6595, Japan
}

(Received September 4, 1997)

\begin{abstract}
Age and growth of the anglerfish Lophiomus setigerus were examined using vertebral centra from specimens collected in the East China Sea during the period from March 1991 to February 1996. Monthly changes in the frequency of appearance of a translucent band on the outer margin of the centrum and in the marginal increments indicated that ring marks form once a year, primarily from November through December. The body proportional hypothesis method was used to estimate the back-calculated total lengths. Male specimens possessed 1-8 ring marks while females had 1-11 ring marks. Using the back-calculated total lengths, growth of male anglerfish was expressed as $T L_{t}=379.2\left(1-\mathrm{e}^{-0.193(t-0.300)}\right)$ $(t \leqq 8)$ and $T L_{t}=528.4\left(1-\mathrm{e}^{-0.140(t-0.264)}\right)(t \leqq 11)$ for females. Our results suggested that females grow faster and live longer than males.
\end{abstract}

Key words: Lophiomus setigerus, anglerfish, age, growth, centrum, East China Sea

The anglerfish Lophiomus setigerus is widely distributed in the western Pacific, the Indian Ocean and the Red Sea. ${ }^{1,2)}$ In the East China Sea, anglerfish are typically caught at depths of $75-85 \mathrm{~m}$ in water with a temperature ranging from $17-20^{\circ} \mathrm{C}$, during the autumn. ${ }^{3)}$ Tokimura ${ }^{4)}$ reported that the distribution of $L$. setigerus in the East China Sea does not change throughout the year; whereas seasonal variations occur in the distribution of Lophius litulon in the East China and Yellow Seas. ${ }^{3-5)}$ These anglerfishes are the occasional target species of trawl fisheries during the winter months in the coastal waters of Japan and from the East China Sea to the Yellow Sea, because of their high market value. However, little information is available for the assessment and management of the fisheries of these two anglerfish species. Yamada ${ }^{3)}$ showed that spawning of $L$. setigerus occurs during the period from April through May in the East China Sea. Yoneda et al.,") however, suggested that females undergo repeated spawnings between May and November.

Earlier reports on the size of L. setigerus include disparate information. One finding is that anglerfish larger than $30-35 \mathrm{~cm}$ total length are rarely caught in the East China Sea. ${ }^{3), * 6}$ Another is that anglerfish reach approximately $1 \mathrm{~m}$ in body length. ${ }^{7), * 7}$ There has been only one study on age and growth of anglerfish in the East China Sea using analysis of length-frequency distributions. ${ }^{* 6}$ This study grouped the data from the two sexes together. To date, no study on age and growth of anglerfish using any hard structures has been performed. In this paper, we examined the age and growth of anglerfish in the East China Sea using vertebral centra.

\section{Materials and Methods}

A total of 1186 anglerfish were collected from a commercial trawl fishery and from three trawl surveys conducted by the Seikai National Fisheries Research Institute (SNFRI), National Fisheries University, and Nagasaki University, during the period from March 1991 to February 1996 in the East China Sea (Fig. 1).

All specimens were measured to the nearest millimeter in total length (TL) and to the nearest gram in body weight $(B W)$. The masses of the gonads and livers were determined to the nearest $0.1 \mathrm{~g}$ and the gonads were preserved in Bouin's solution or $10 \%$ formalin for subsequent histological observations and fecundity estimates.

Vertebral centra were chosen as the optimal hard structure for use as a marker in age determination, based on a preliminary examination revealing that each centrum contained concentric bands that appeared to be ring marks (Fig. 2). Otoliths, basihyals, metapterygoids, pelvis, actinosts, and illiciums were also examined; however, these structures were either opaque or had extremely irregular outer margins, making it difficult or impossible to clearly discern ring marks.

Vertebra number 8 was used for age determination. Ver-

\footnotetext{
${ }^{* 6}$ M. Tokimura et al.: Abst. Metg. Japan. Soc. Fisheries Sci., April, 1990, p. 9 (in Japanese).

${ }^{*_{7}}$ T. Suzuuchi: Kiankou ni tsuite [Report on Lophius litulon]. Hokusuishi Dayorí, Hokkaido Chuo Fish. Exp. Stn., 22, 1993, pp. 29-31 (in Japanese).
} 


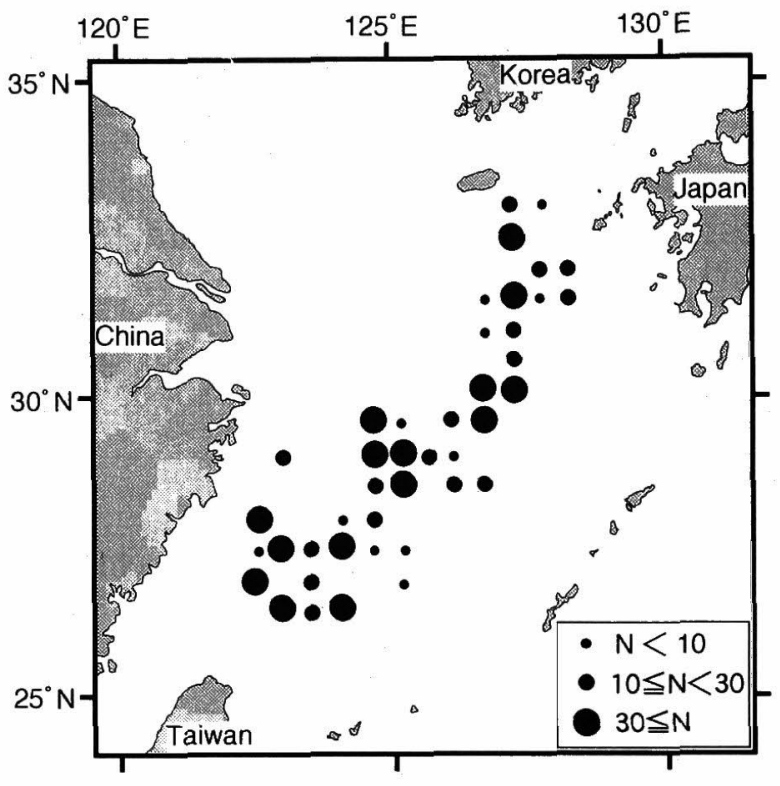

Fig. 1. Geographical distribution of specimens of $L$. setigerus collected in the East China Sea. N, number of fish examined.

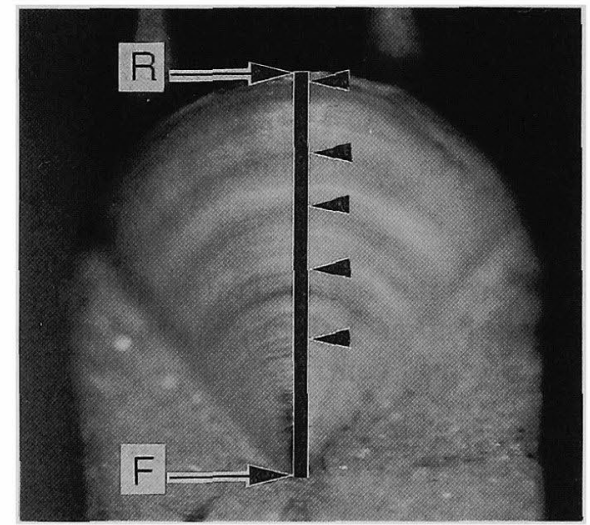

Fig. 2. Ring mark reading of vertebral centrum of $L$. setigerus Arrowhead indicates the ring mark on the outer margin of the translucent band used for ring radius measurements. F, focus; $R$, centrum radius.

tebra number 7 or 9 was used if number 8 was damaged in preparation. After the marker vertebrae were soaked in hot water and cleaned, they were sectioned mid-frontally and the dorsal parts used for examination. Ring marks on the anterior face of the centrum were counted and measured using a reflected light profile projector at 5-10 $\times$ magnification. A broad, opaque band and a narrow, translucent band appeared alternately on the centrum surface. Any translucent band that completely encircled the centrum surface was considered a "true band" and was counted, and one that did not was considered a "false band" and was not counted. A total of 963 specimens (81\%) was used for age determination. The distance from the focus $(F)$ to the outer margin of the translucent band of each ring mark (ring radius, $r_{n}$ ) and the centrum radius $(R)$ were measured on a transverse plane along a straight line through the focus (Fig. 2).

The marginal increment of the centrum $(M I)$ was examined using specimens possessing 1-6 ring marks based on the following equation:

$$
M I=\left(R-r_{\max }\right) /\left(r_{\max }-r_{\max -1}\right)
$$

where $R$ is the centrum radius ( $\mathrm{mm}$ ) and $r_{\max }$ is the distance $(\mathrm{mm})$ between the focus and the outer margin of the last translucent band.

Logarithmic equations were used to relate fish total length at capture $(T L)$ to the centrum radius at capture $(R)$ for each sex.

$$
\log _{e} T L=a+b \log _{e} R
$$

The logarithmic equations yielded higher $r^{2}$ values than alternative models. Back-calculation relationships were based on the body proportional hypothesis (BPH) method. ${ }^{8)}$ According to Francis, ${ }^{8)}$ the BPH procedure is described by the following equation:

$$
T L_{n}=\left(r_{n} / R\right)^{b} T L
$$

where $T L_{n}$ is the back-calculated $T L$ at the $n$-th ring and $b$ is the slope calculated from the logarithmic regression of $T L$ versus $R$ (1).

To evaluate growth of males and females, the mean back-calculated $T L s$ were fitted to the von Bertalanffy growth equation using the Marquardt method.,10)

\section{Results}

\section{Length frequency distribution}

Females $(n=765)$ were significantly larger in $T L$ than males ( $n=421$; Mann-Whitney U-test, $P<0.001$; Fig. 3 ). Length frequency distributions clearly showed differences in the range of sizes between each of the sexes: most males sampled ranged from 200 to $300 \mathrm{~mm} T L$ and females from 300 to $400 \mathrm{~mm} T L$. The maximum size of any of the males was $350 \mathrm{~mm} T L$ and the largest of the females had a body length of $428 \mathrm{~mm} T L$.

\section{Period of Ring Mark Formation}

In order to define clearly the period of ring mark formation, monthly changes in the frequency of appearance of the translucent band on the outer margin of the centrum as well as the $M I$ of the centrum were examined. None of the samples examined during the period from January to May possessed a translucent band on the outer margin of the centrum (Fig. 4). The frequency of the appearance of the translucent band on the outer margin of the centrum remained high between August and October and decreased sharply from November through December. The fewest $M I$ s having new opaque bands occurred during the period from September through December (Fig. 5). The mean MI increased in January and reached a maximum during August through October. These results suggest that ring marks form once a year, between September and December (primarily in November through December), and can be considered as an annual mark.

\section{$T L-R$ Relationships and Back-calculated TL}

Regression analysis of the relationship between the $\log$ $T L(\mathrm{~mm})$ and $\log R$ (mm) for each sex was linear (Fig. 6):

Male: $\log _{e} T L=4.41+0.77 \log _{e} R\left(n=340, r^{2}=0.89\right)$

Female: $\log _{e} T L=4.41+0.79 \log _{e} R\left(n=623, r^{2}=0.94\right)$ 

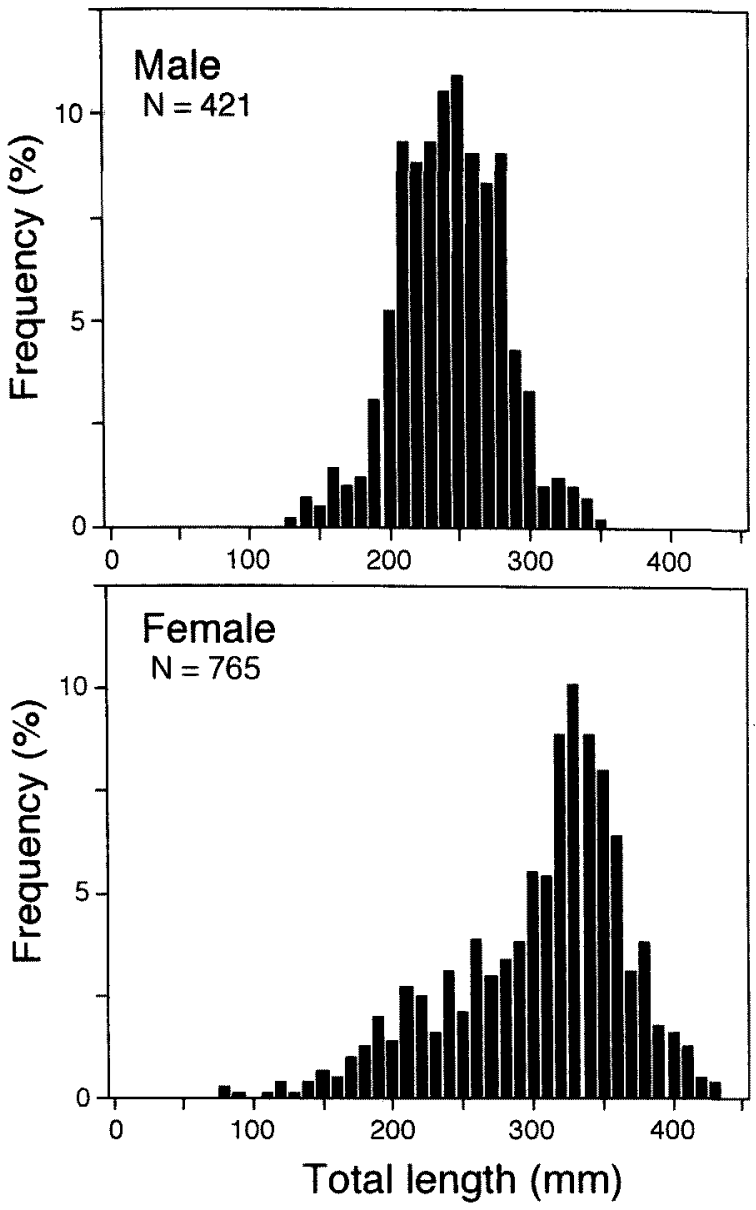

Fig. 3. Length-frequency distribution of $L$. setigerus sampled from the East China Sea. N, number of fish examined.

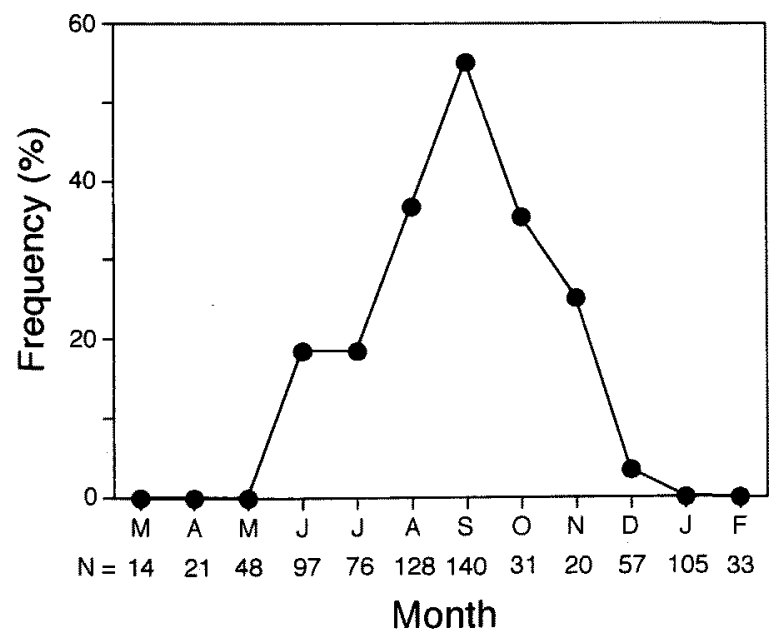

Fig. 4. Monthly changes in the frequency of appearance of a translucent band on the outer margin of the centrum of L. setigerus. $\mathrm{N}$, number of fish examined.

In the regression analysis of the relationship between $\log$ $T L$ and $\log R$, significant differences occurred in both the intercept and the slope for both sexes (ANCOVA, $P<0.01)$. The data were thus treated separately for each sex.

The $T L s$ of each fish were back-calculated to the time of formation of the $n$-th annulus from each radius using the BPH method (2). The mean back-calculated $T L s$ of each

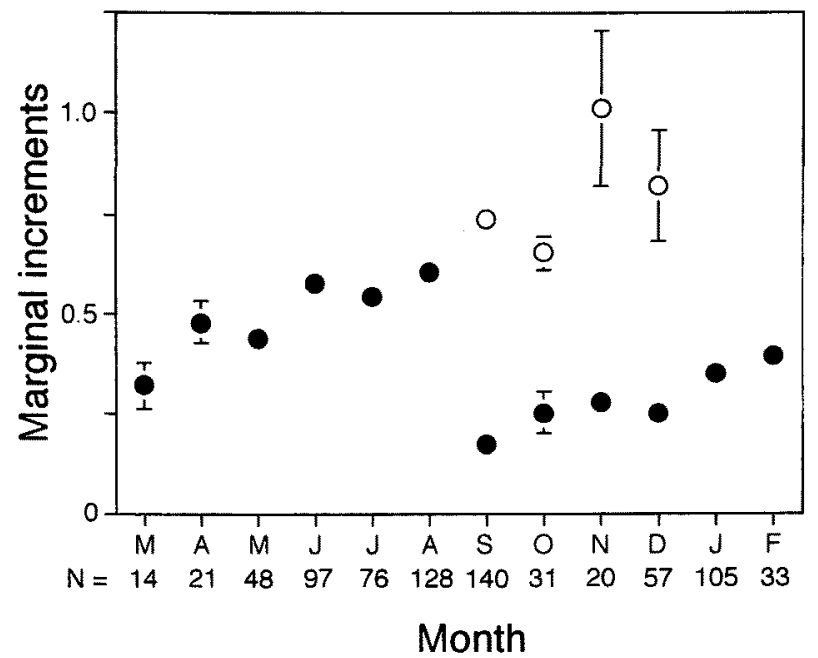

Fig. 5. Monthly changes in the mean marginal increment of the centrum $\left(r_{1-6}\right)$ of $L$. setigerus (closed circles).

Open circles indicate the mean marginal increments of centra without new opaque bands observed during the period between September and December. Vertical bars indicate standard error. N, number of fish examined.
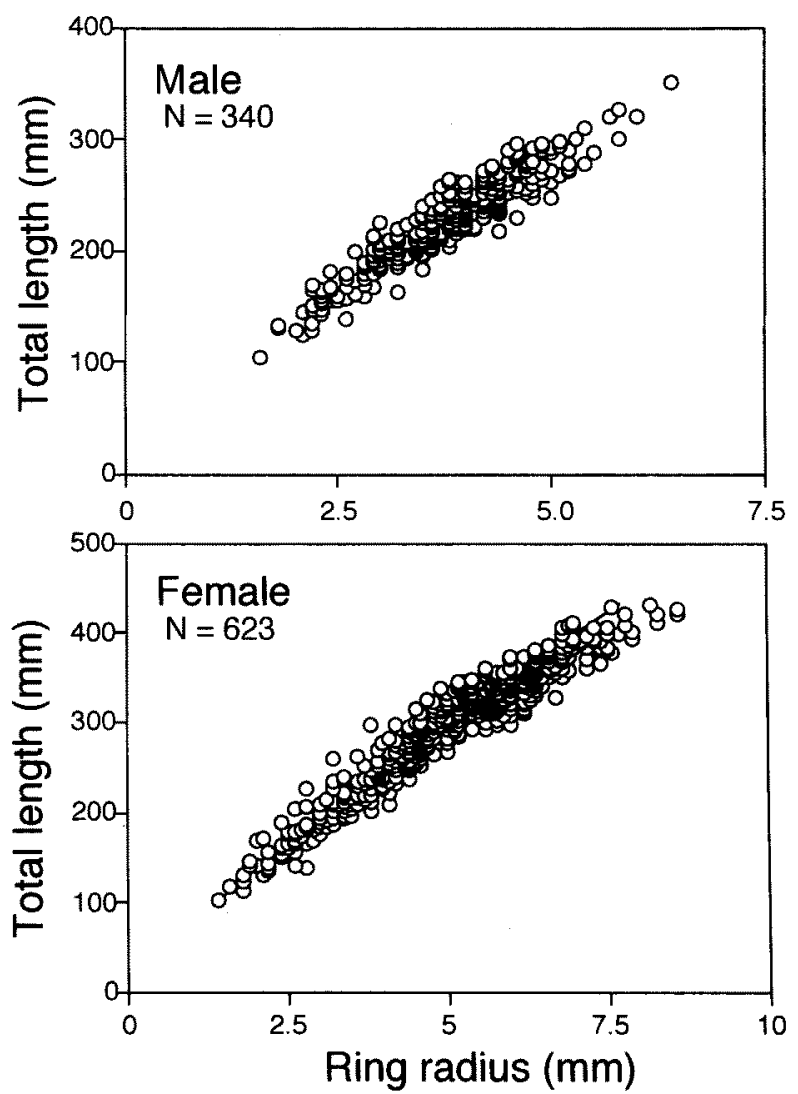

Fig. 6. Relationship between total length and the centrum radius for male and female $L$. setigerus. $\mathrm{N}$, number of fish examined.

successive centrum annulus at the time of annulus formation are shown in Tables 1 and 2. The centrums from males had 1 to 8 rings, while those from females had 1 to 11 rings. Neither a clear Lee's, nor a reversed Lee's phenomenon was found for the mean back-calculated $T L s$ of males and females. 


\section{Growth}

The spawning season of anglerfish in the East China Sea occurs from May to November. ${ }^{\text {) }}$ However, the annual ring marks were formed between September and December (primarily in November through December), about three or four months after the middle of the spawning season. Thus, the mean back-calculated TLs estimated by the two methods for each sex and age $(t+0.3)$ were fitted to the von Bertalanffy growth equation (Fig. 7):

$$
\begin{aligned}
& \text { Male: } T L_{t}=379.2\left(1-\mathrm{e}^{-0.193(t-0.300)}\right)(t \leqq 8) \\
& \text { Female: } T L_{t}=528.4\left(1-\mathrm{e}^{-0.140(t-0.264)}\right)(t \leqq 11)
\end{aligned}
$$

The growth curves indicated that the growth trends of both sexes were similar until age 2 , but that females grew faster than males over age 3 (Fig. 7).

The relationship between $B W(\mathrm{~g})$ and $T L(\mathrm{~mm})$ for each sex was determined using the following equation (Fig. 8):

$$
\begin{gathered}
\text { Male: } \begin{aligned}
\log _{e} B W= & -10.57+2.95 \log _{e} T L \\
& \left(n=421, r^{2}=0.90\right)
\end{aligned} \\
\text { Female: } \log _{e} B W=-11.45+3.12 \log _{e} T L \\
\left(n=765, r^{2}=0.94\right)
\end{gathered}
$$

\begin{tabular}{|c|c|c|c|c|c|c|c|c|c|}
\hline Ring group & $N$ & $T L_{1}$ & $T L_{2}$ & $T L_{3}$ & $T L_{4}$ & $T L_{5}$ & $T L_{6}$ & $T L_{7}$ & $T L_{8}$ \\
\hline 1 & 2 & 72 & & & & & & & \\
\hline 2 & 28 & 74 & 130 & & & & & & \\
\hline 3 & 76 & 65 & 130 & 177 & & & & & \\
\hline 4 & 98 & 65 & 125 & 170 & 208 & & & & \\
\hline 5 & 82 & 62 & 121 & 167 & 204 & 236 & & & \\
\hline 6 & 40 & 58 & 116 & 158 & 198 & 231 & 258 & & \\
\hline 7 & 9 & 68 & 119 & 160 & 195 & 229 & 258 & 280 & \\
\hline 8 & 5 & 66 & 121 & 161 & 193 & 220 & 252 & 279 & 302 \\
\hline \multicolumn{10}{|c|}{340} \\
\hline Mean (weighted & & 64 & 124 & 169 & 204 & 233 & 257 & 279 & 302 \\
\hline
\end{tabular}

This analysis showed that significant differences occurred in both the intercept and the slope for both sexes (ANCOVA, $P<0.01)$.

Table 1. Mean back-calculated total lengths $(\mathrm{mm})$ at each ring group for male $L$. setigerus

$N$, number of fish examined.

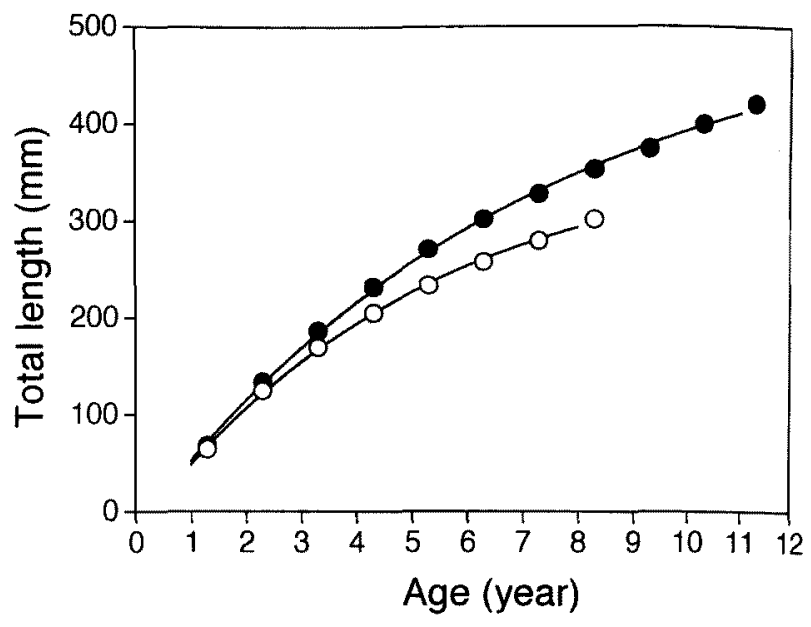

Fig. 7. von Bertalanffy growth curve for male (open circles) and female (closed circles) L. setigerus.

Circles are the back-calculated total length at ring formation.

\section{Discussion}

This is the first report on age and growth of male and female anglerfish in the East China Sea using the vertebral centra as an age determinant marker. Our findings indicate that there are differences both in the growth increment and in the maximum age between males and females, reflected in the fact that most of the larger specimens are females. This was also found to be true for L. litulon ${ }^{5}$ in the East China Sea and Yellow Sea.

Age determination markers of lophiidae fishes have been agreed upon as otolith, ${ }^{11,12)}$ illicium, ${ }^{13)}$ and vertebral centrum. ${ }^{5.14)}$ The sagittal otoliths are the most popular hard structure used for age determination. ${ }^{15-17)}$ The otoliths of $L$. setigerus, however, had extremely irregular outer margins and did not reveal clearly discernible ring marks. This was also true for Lophius americanus ${ }^{14)}$ and L. litulon. ${ }^{5)}$ Age determination for Lophitus piscatorius, Lophius budegassa, ${ }^{11)}$ and Lophius upsicephalus ${ }^{12)}$ used otoliths, which are extremely variable in shape. Griffiths

\begin{tabular}{|c|c|c|c|c|c|c|c|c|c|c|c|c|}
\hline Ring group & $N$ & $T L_{1}$ & $T L_{2}$ & $T L_{3}$ & $T L_{4}$ & $T L_{5}$ & $T L_{6}$ & $T L_{7}$ & $T L_{8}$ & $T L_{9}$ & $T L_{10}$ & $T L_{11}$ \\
\hline 1 & 3 & 87 & & & & & & & & & & \\
\hline 2 & 36 & 74 & 135 & & & & & & & & & \\
\hline 4 & 75 & 69 & 139 & 192 & 239 & & & & & & & \\
\hline 5 & 129 & 68 & 137 & 192 & 238 & 280 & & & & & & \\
\hline 6 & 159 & 69 & 135 & 188 & 234 & 274 & 309 & & & & & \\
\hline 8 & 42 & 62 & 123 & 174 & 218 & 259 & 293 & 327 & 356 & & & \\
\hline 9 & 15 & 65 & 123 & 169 & 208 & 249 & 284 & 319 & 348 & 372 & & \\
\hline 10 & 7 & 67 & 129 & 177 & 218 & 255 & 287 & 322 & 357 & 384 & 402 & \\
\hline \multirow[t]{2}{*}{11} & 3 & 68 & 128 & 178 & 218 & 253 & 283 & 316 & 346 & 372 & 397 & 421 \\
\hline & 623 & & & & & & & & & & & \\
\hline Mean (weighted) & & 68 & 133 & 186 & 231 & 270 & 302 & 328 & 354 & 375 & 400 & 421 \\
\hline
\end{tabular}
and Hechet $^{(2)}$ conclude that the sagittal otoliths are the only structures that can be used with any degree of confidence for estimates of the length-at-age of $L$. upsicephalus. Spines are commonly used for age determination of

Table 2. Mean back-calculated total lengths $(\mathrm{mm})$ at each ring group for female L. setigerus

$N$, number of fish examined. 


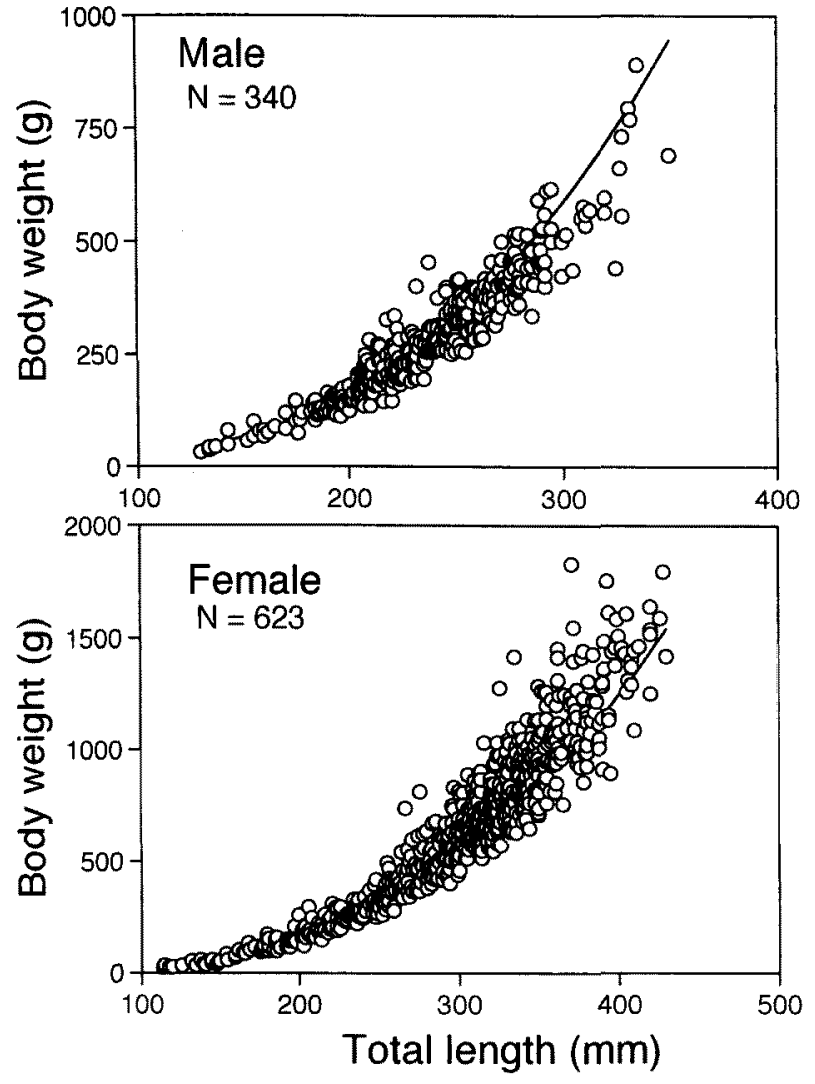

Fig. 8. Relationship between total length and body weight for male and female $L$. setigerus. $\mathrm{N}$, number of fish examined.

sharks. ${ }^{18,19)}$ Dupouy et al..$^{13)}$ developed the method of illicium sectioning for age determination in $L$. budegassa and $L$. piscatorius, but the illiciums of $L$. setigerus were not composed of concentric ring marks. The vertebral centra are the most commonly used age determinant for elasmobranches. ${ }^{20-24)}$ Even though false bands were often observed on the surface of the centrum of $L$. setigerus, age determination in that species, as well as in L. americanus ${ }^{14)}$ and L. litulon, ${ }^{5)}$ was dependent on the occurrence of concentric bands (as true bands) on the surface of the centrum. The vertebral centrum may be a suitable structure for age determination of some lophiidae fishes.

The maximum size of any specimen from the 1186 sampled was $428 \mathrm{~mm} T L$ for a female. Our length-frequency distributions showed that a large number of specimens of both males and females were less than $400 \mathrm{~mm} T L$. This is in agreement with the report of Yamada ${ }^{3)}$ and Tokimura et $a l .{ }^{* 6}$ on anglerfishes in the East China Sea. From the trawl survey conducted by SNFRI, all of the $L$. setigerus caught were less than $450 \mathrm{~mm} T L$ except for a single specimen of $500 \mathrm{~mm} T L$ over (U. Yamada and M. Tokimura: Seikai Natl. Fish. Res. Inst., pers. comm.). These findings are quite different from previous information reporting anglerfish reaching approximately $1 \mathrm{~m}$ in body length $(B L) .^{7), * 7}$ In the herring Clupea pallasii, ${ }^{25)}$ the pacific cod Gadus macrocephalus, ${ }^{15)}$ the starspotted dogfish Mustelus manazo, ${ }^{24)}$ and the pointhead flounder Hippoglossoides pinetorum, ${ }^{16}$ differences occur in growth rate and lifespan among different waters and/or subpopulations. Furthermore, in the weakfish Cynoscion regalis ${ }^{17}$ from Chesapeake Bay, historic changes in maximum size and age have been reported due to large fluctuations in year-class abundance. To our knowledge, no information about the age and growth of anglerfish in waters other than those discussed here has been reported. Conversely, L. litulon ${ }^{5, * 6}$ do reach sizes greater than $1 \mathrm{~m} T L$, and there is a close resemblance between $L$. litulon and $L$. setigerus. The previous finding that $L$. setigerus reach sizes of approximately $1 \mathrm{~m} B L$ seems likely to be due to mistaking the two species of anglerfish.

The ring radius of each individual correlated very well with total length within each of the sexes, although regression analysis of the relationship between the $\log T L$ and $\log R$ demonstrated that significant differences occur between the sexes. Figure 6 shows that the growth rate of the ring radius in larger females (larger than about $300 \mathrm{~mm}$ $T L$ ) appears to be different from that of smaller females (smaller than about $300 \mathrm{~mm} T L$ ). As a female anglerfish reaches $50 \%$ sexual maturity at $303 \mathrm{~mm} T L$ in the East China Sea (M. Yoneda and S. Matsuura: Kyushu Univ., unpubl. data), the relationship between $T L$ and $R$ for sexually immature $(<303 \mathrm{~mm} T L, n=252)$ and mature $(\geq 303$ $\mathrm{mm} T L, n=371$ ) females was reexamined. The reanalysis demonstrated that statistically significant differences occurred between immature and mature individuals as reflected in the value of the slope (ANCOVA, $P<0.001$ ). On the other hand, in male anglerfish no significant differences occurred in either the intercept or the slope between sexually immature ( $<178 \mathrm{~mm} T L, \mathrm{M}$. Yoneda and S. Matsuura: Kyushu Univ., unpubl. data, $n=37)$ and mature $(\geq 178$ mm $T L, n=303$ ) individuals. The morphological changes and size variation of each vertebral centrum with respect to fish growth have been reported for many fishes. ${ }^{26-29)}$ In the jack mackerel Trachurus japonicus, ${ }^{27)}$ transitional points in vertebral length growth rate are found twice during its life history; firstly at the fry stage and secondly at the end of 1 year, which is possibly related to sexual maturity. We found that the ovarian weight of anglerfish markedly increased to about half of the body mass just before spawning, and that the liver weight of mature females changed significantly with seasonal cycles and ovarian development. The vertebra used for age determination in the present study (No. 7, 8 or 9) is located at the midpoint of the vertebral column and above the posterior portion of the abdominal cavity. This suggests that the transition in the vertebral radius (No. 8) growth rate of females may be caused by the extraordinary variance of the visceral condition between sexually immature and mature individuals.

In this study, the body proportional hypothesis (BPH) method was used to estimate back-calculated total lengths. Francis ${ }^{8)}$ described all the proportional methods in detail and attempted to classify them by the assumptions implied by their formulas. $\mathrm{He}^{8}$ concluded that the body proportional hypothesis and scale proportional hypothesis methods are preferable to others because of their solid theoretical bases. Smedstad and Holm ${ }^{30)}$ compared the sixth back-calculation formula for cod otoliths with the actual fish length, and reported that the non-linear body proportional hypothesis appeared to give the best results for cod otoliths.

Our findings indicate that the estimated $T L$ at each age for females is larger than that of males, and that the observed longevity for females is greater than for males, 
which is consistent with the sex-specific length-frequency distributions. This may contribute to the differences in size at sexual maturity (M. Yoneda and S. Matsuura: Kyushu Univ., unpubl. data). This same finding applies to $L$. litulon. ${ }^{5)}$ Although the growth differences between the sexes of $L$. americanus $^{14)}$ and $L$. piscatorius ${ }^{11,13)}$ are less than those observed for $L$. setigerus, in these Lophius spp. ${ }^{14,31)} \mathrm{fe}-$ males attain sexual maturity at a larger size than males. It is likely that differential growth rates and size at sexual maturity for both sexes are common sexual dimorphisms of lophiidae fishes.

Only one report on age and growth of $L$. setigerus indicates that anglerfish reach approximately 150, 230, and $300 \mathrm{~mm} T L$ at 2,3 , and 4 years old, respectively. ${ }^{* 6}$ However, our results using vertebral centra differ from the previous study, which used length-frequency distribution data for combined sexes. Our length frequency distributions showed that most of the larger individuals $(>300$ $\mathrm{mm} T L$ ) were females. Furthermore, the spawning season of $L$. setigerus ${ }^{6}$ in the East China Sea occurs over a long period from May to November, and the present study suggests that females grow faster and live longer than males. These findings clearly suggest that cohorts would not occur in the length-frequency distribution from data combining both anglerfish sexes. This difference in data treatment is the likely reason for the large difference between the results of the earlier studies and those reported here.

Acknowledgments We are grateful to Captain Y. Kimura and the crew of the "No. 21 Yamada Maru" of the Yamada Suisan Limited Company, and to the officers and crew of the Training Ship "Nagasaki Maru" of Nagasaki University, for allowing us to board their vessels and collect specimens. We also thank Dr. T. Hamano of National Fisheries University for his kind advice on the statistical analyses, and anonymous reviewers.

\section{References}

1) J. H. Caruso: The systematics and distribution of the lophiid anglerfishes: Revisions of the genera Lophiomus and Lophius. Copeia, 1983, 11-30 (1983).

2) J. H. Caruso: Comments on the taxonomic status of Lophiodes quinqueradiatus (Brauer), with the first record of Lophiomus setigerus (Vahl) from the Red Sea (Pisces: Lophiidae). Copeia, 1989, $1072(1989)$.

3) U. Yamada: Lophiomus setigerus and Lophius litulon, in "Fishes of the East China Sea and the Yellow Sea" (ed. by U. Yamada, M. Tagawa, S. Kishida, and K. Honjo), Seikai Regional Fisheries Research Laboratory, Nagasaki, 1986, pp. 106-109.

4) M. Tokimura: Distribution of primary bottom-fishes in the East China Sea and the Yellow Sea during the winter season of 1991. Seikai Block Sokouo Chosa Kenkyu Kaiho, 3, 15-39 (1992) (in Japanese)

5) M. Yoneda, M. Tokimura, H. Fujita, N. Takeshita, K. Takeshita, M. Matsuyama, and S. Matsuura: Age and growth of anglerfish Lophius litulon in the East China Sea and the Yellow Sea. Fisheries Sci., 63, 887-892 (1997).

6) M. Yoneda, M. Tokimura, H. Fujita, N. Takeshita, K. Takeshita, M. Matsuyama, and S. Matsuura: Ovarian structure and batch fecundity in anglerfish, Lophiomus setigerus (Vahl). J. Fish Biol., 52, 94-106 (1998).

7) A. Ochiai and M. Tanaka: Lophius litulon and Lophiomus setigerus, in "Ichthyology (the second volume)", Koseisha Koseikaku, Tokyo, 1986, pp. 635-638 (in Japanese).

8) R. I. C. C. Francis: Back-calculation of fish length: a critical review. J. Fish Biol., 36, 883-902 (1990).

9) N. R. Draper and H. Smith: Applied regression analysis (Translat- ed from Japanese by K. Nakamura), Morikita Shuppan, Tokyo, 1966, pp. 261-302.

10) T. Akamine: A mathematical study of fish growth formula in population dynamics. Bull. Natl. Res. Inst. Fish. Sci., 7, 189-263 (1995).

11) N. C. Tsimenidis and J. C. Ondrias: Growth studies on the anglerfishes Lophius piscatorius L., 1758 and Lophius budegassa Spinola, 1807 in Greek waters. Thalassographica, 2, 63-94 (1980).

12) M. H. Griffiths and T. Hecht: A preliminary study of age and growth of the monkfish Lophius upsicephalus (Pisces: Lophiidae) on the Agulhas Bank, south Africa. S. Afr. J. Mar. Sci., 4, 51-60 (1986).

13) H. Dupouy, R. Pajot, and B. Kergoat: Study on age and growth of the anglerfishes, Lophius piscatorius and $L$. budegassa, from northeast Atlantic using illicium. Rev. Trav. Inst. Pèches Marit., 48, 107-131 (1986).

14) M. P. Armstrong, J. A. Musick, and J. A. Colvocoresses: Age, growth, and reproduction of the goosefish, Lophius americanus (Pisces: Lophiiformes). Fish. Bull., 90, 217-230 (1992).

15) T. Hattori, Y. Sakurai, and K. Shimazaki: Age determination by sectioning of otoliths and growth pattern of pacific cod. Nippon Suisan Gakkaishi, 58, 1203-1210 (1992).

16) O. Tominaga, K. Inoguchi, Y. Watanabe, M. Yamaguchi, T. Nakatani, and T. Takahashi: Age and growth of pointhead founder Hippoglossoides pinetorum in Ishikari Bay, Hokkaido. Fisheries Sci., 62, 215-221 (1996).

17) S. K. Lowerre-Barbieri, M. E. Chittenden Jr., and L. R. Barbieri: Age and growth of weakfish, Cynoscion regalis, in the Chesapeake Bay region with a discussion of historical changes in maximum size. Fish. Bull., 93, 643-656 (1995).

18) M. J. Holden and P. S. Meadows: The structure of the spine of the spur dogfish (Squalus acanthias L.) and its use for age determination. J. Mar. Biol. Ass. U.K., 42, 179-197 (1962).

19) R. J. Beamish and G. A. McFarlane: Annulus development on the second dorsal spine of the spiny dogfish (Squalus acanthias) and its validity for age determination. Can. J. Fish. Aquat. Sci., 42, 17991805 (1985).

20) R. Ishiyama: Studies on the rays and skates belonging to the family Rajidae, found in Japan and adjacent regions. (3). Age determination of Raja hollandi Jordan et Richardson, chiefly inhabiting in the waters of the East China Sea. Nippon Suisan Gakkaishi, 16, 119-124 (1951).

21) F. C. Daiber: A technique for age determination in the skate, Raja eglanteria. Copeia, 1960, 258-260 (1960).

22) G. M. Cailliet, K. G. Yudin, S. Tanaka, and T. Taniuchi: Growth characteristics of two populations of Mustelus manazo from Japan based upon cross-readings of vertebral bands. NOAA Tech. Rep. NMFS, 90, 167-176 (1990).

23) K. G. Yudin and G. M. Cailliet: Age and growth of the gray smoothhound, Mustelus californicus, and the brown smoothhound, $M$. henlei, sharks from central California. Copeia, 1990, 191-204 (1990).

24) A. Yamaguchi, T. Taniuchi, and M. Shimizu: Age and growth of the starspotted dogfish Mustelus manazo from Tokyo Bay, Japan. Fisheries Sci., 62, 919-992 (1996).

25) Y. Kanno: Comparison of age composition, sex ratio and growth rate among populations of herring Clupea pallasii in the Far Eastern waters. Nippon Suisan Gakkaishi, 55, 583-589 (1989).

26) C. R. Clothier: Vertebral variation with size in Clevelandia ios. Copeia, 1946, 113-116 (1946)

27) T. Yamada: Studies on the vertebral length curve of the jack mackerel. Bull. Fac. Fish. Nagasaki Univ., 10, 192-209 (1961).

28) T. Yamada: On the vertebral length curve of teleosts. Nippon Suisan Gakkaishi, 27, 510-515 (1961).

29) N. Komada: Growth of vertebral centra in the cyprinid fish, Tribolodon hakonesis. Japan. J. Ichthyol., 26, 351-356 (1980).

30) O. M. Smedstad and J. C. Holm: Validation of back-calculation formulae for cod otoliths. J. Fish Biol., 49, 973-985 (1996).

31) I. P. Afonso-Dias and J. R. G. Hislop: The reproduction of anglerfish Lophius piscatorius Linnaeus from the north-west coast of Scotland. J. Fish Biol., 49 (Supplement A), 18-39 (1996). 